\title{
"Estimating the value-at-risk of JSE indices and South African exchange rate with Generalized Pareto and stable distributions"
}

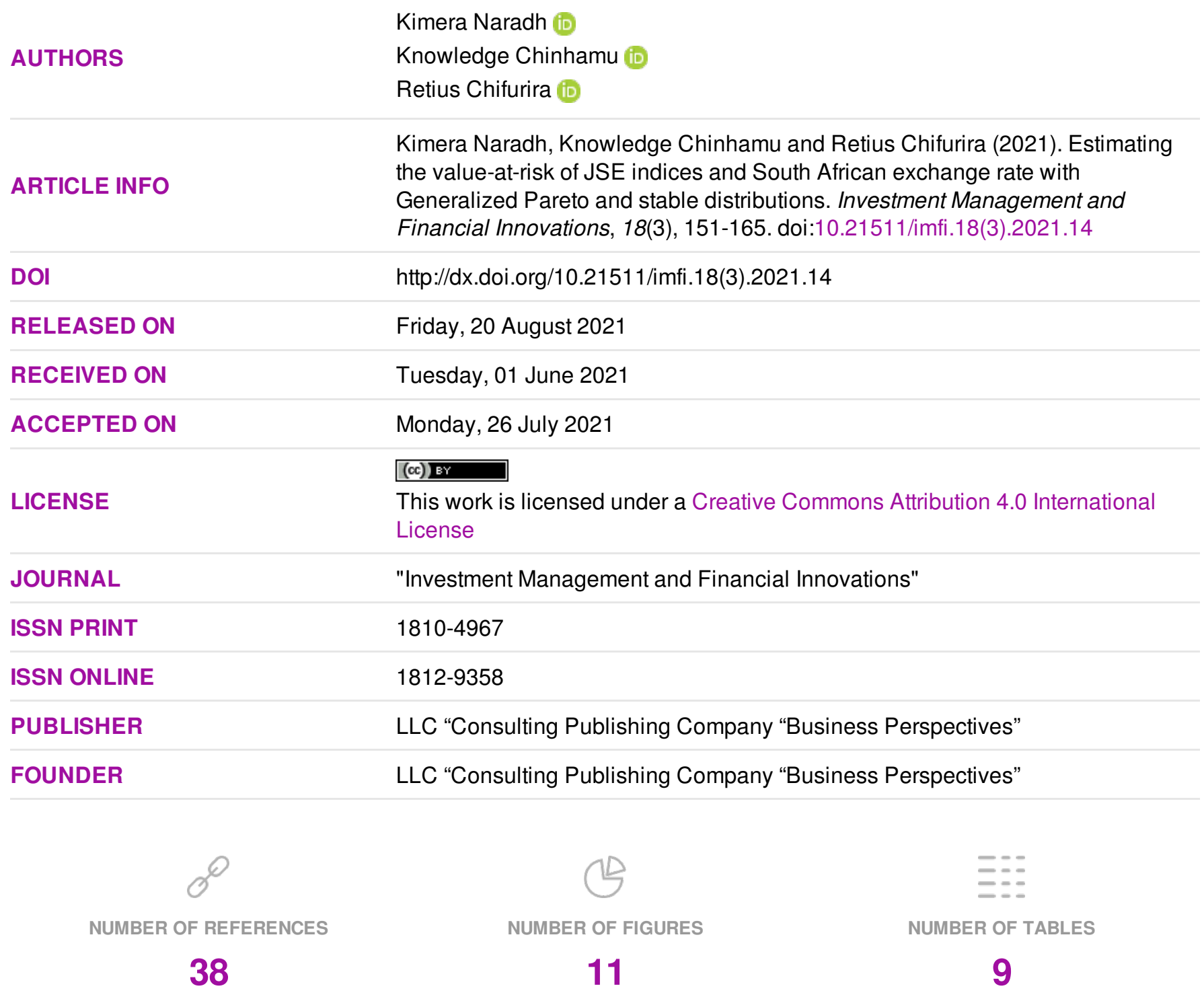

(C) The author(s) 2021. This publication is an open access article. 


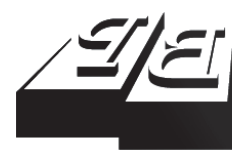

\section{BUSINESS PERSPECTIVES}

(O)

LLC "CPC "Business Perspectives"

Hryhorii Skovoroda lane, 10 Sumy, 40022, Ukraine www.businessperspectives.org
Received on: $1^{\text {st }}$ of June, 2021 Accepted on: $26^{\text {th }}$ of July, 2021 Published on: $20^{\text {th }}$ of August, 2021

(C) Kimera Naradh, Knowledge Chinhamu, Retius Chifurira, 2021

Kimera Naradh, MSc, Ph.D. Student, School of Mathematics, Statistics and Computer Science, University of KwaZulu-Natal, South Africa.

Knowledge Chinhamu, Ph.D., Senior Lecturer, School of Mathematics, Statistics and Computer Science, University of KwaZulu-Natal, South Africa.

Retius Chifurira, Ph.D., Senior Lecturer, School of Mathematics, Statistics and Computer Science, University of KwaZulu-Natal, South Africa. (Corresponding author)
Kimera Naradh (South Africa), Knowledge Chinhamu (South Africa), Retius Chifurira (South Africa)

\begin{abstract}
South Africa's economy has faced many downturns in the previous decade, and to curb the spread of the novel SARS-CoV-2, the lockdown brought South African financial markets to an abrupt halt. Therefore, the implementation of risk mitigation approaches is becoming a matter of urgency in volatile markets in these unprecedented times. In this study, a hybrid generalized autoregressive conditional heteroscedasticity (GARCH)-type model combined with heavy-tailed distributions, namely the Generalized Pareto Distribution (GPD) and the Nolan's S0-parameterization stable distribution (SD), were fitted to the returns of three FTSE/JSE indices, namely All Share Index (ALSI), Banks Index and Mining Index, as well as the daily closing prices of the US dollar against the South African rand exchange rate (USD/ZAR exchange rate). VaR values were estimated and back-tested using the Kupiec likelihood ratio test. The results of this study show that for FTSE/JSE ALSI returns, the hybrid exponential GARCH $(1,1)$ model with SD model (EGARCH $(1,1)-S D)$ outperforms the GARCH GPD model at the 2.5\% VaR level. At VaR levels of $95 \%$ and $97.5 \%$, the fitted GARCH $(1,1)$-SD model for FTSE/JSE Banks Index returns performs better than the GARCH $(1,1)$-GPD. The fitted GARCH $(1,1)$-SD model for FTSE/JSE Mining Index returns is better than the GARCH $(1,1)-$ GPD at $5 \%$ and $97.5 \%$ VaR levels. Thus, this study sug gests that the GARCH $(1,1)$-SD model is a good alternative to the VaR robust model for modeling financial returns. This study provides salient results for persons interested in reducing losses or obtaining a better understanding of the South African financial industry.
\end{abstract}

\section{Keywords}

GARCH-type models, Generalized Pareto Distribution, backtesting, Nolan's S0-parameterization-stable distributions, value-at-risk

\section{JEL Classification $\quad$ C22, C58, G32}

\section{INTRODUCTION}

In the recent past, the South African financial industry has experienced a whirlwind of challenges due to several isolated disruptive global or domestic events, the most recent being the COVID-19 pandemic. The South African government, like many governments across the world, declared a national state of disaster, and such decisions caused detrimental impacts on the global economy. Stunted growth, market disruptions and consumer uncertainty are some of the numerous negative effects that have arisen as a result. Nel et al. (2020) stress that financial institutions should remain hyper-vigilant and impose proper risk management and mitigation strategies for business continuity.

In these circumstances, understanding the volatile characteristics of the financial market becomes of key interest in formulating tactical strategies to cope with unexpected disadvantageous events. 
Appropriate and reliable models that capture the stylized properties of financial data are recommended. Literature suggests dependency on the generalized autoregressive conditional heteroscedasticity $(\mathrm{GARCH})$ framework in dealing with observed volatility in finance (Jafari et al., 2007). However, even with the success of GARCH models, Mzamane et al. (2013) point out the need for more flexible volatility modelling that caters for the asymmetric effect in financial returns.

To examine this, a Value-at-Risk (VaR) approach with a hybrid GARCH-type model with a heavy tailed distribution extension is investigated for the South African financial market where characteristics of fat tails and high market volatility are apparent.

Policymakers, regulators, risk-averse investors, and insurers could leverage if they identify distributions that adequately capture aspects of financial data and impose risk mitigation approaches. Hence, models that monitor volatile indices and exchange rates, and provide remedies that are useful to investors, are necessary, especially since disruptive events and uncertainty are prevalent in the financial industry for the foreseeable future.

In essence, this study explores the heavy-tailed addition, specifically the generalized Pareto distribution (GPD) and stable distribution (SD) to the standard GARCH model as alternatives to capture signs of asymmetry and volatility clustering to three FTSE/JSE market indices and the US Dollar to the South African Rand, as well as acquire further understanding of the South African financial industry.

\section{LITERATURE REVIEW}

McNeil and Frey (2000) proposed a method for evaluating VaR by using the pseudo-maximum likelihood method to fit GARCH models and Extreme Value Theory (EVT) to analyze the tail of the innovation distribution for the GARCH Model. The data consists of five historical series of log returns, namely: Standard \& Poor's Index (January 1960-1993), DAX Index and BMW index (January 1973 - July 1996), US dollar and British pound (1980-1996), and lastly gold prices (January 1980 - December 1997). This study suggests a conditional approach that models the conditional distribution of asset returns, well suited for estimating VaR. Also, residual distributions are often leptokurtic, and the GPDapproximation is preferred as it can account for asymmetry in the tail.

The application of Extreme Value Theory by Byström (2005) to the case of large electricity prices showed an adequate fit by the GPD distribution. Chifurira and Chinhamu (2017) compared the performance of the GARCH-GPD and GARCHPearson type-IV models when estimating the VaR for the South African Mining Index returns. The main findings suggest that the GARCH-GPD and GARCH-Pearson type-IV models outperform the Generalized Hyperbolic distributions.
Nolan (2003) analyzes the appropriateness of stable distributions to financial data. This study used a maximum likelihood (ML) method to estimate the stable parameters. The paper studied the monthly exchange rates between the U.S. Dollar (USD) and the Tanzanian Shilling and ranged from January 1975 to September 1997 where it was found that the USD/Tanzanian Shilling exchange rate was subject to more extreme fluctuations. The study has shown the practicability of stable parameter estimation, and model diagnostics show that stable distributions describe financial data well. In cases where the fit is imperfect or unsuitable, this study highlights a better fit than that of the Normal Gaussian model and highlights the fittingness of stable distributions in VaR calculations.

Borak et al. (2005) emphasize the empirical evidence by Fama (1965) and Mandelbrot (1963) that suggests stable distributions as a heavy-tailed alternative. Stable distributions consider asymmetry and fat tails and are valued models in view of extreme events such as the global market crisis or natural calamities. Empirical evidence shows a strong fit of stable laws for the DJIA index and Boeing stock.

Ilupeju (2016) researched daily returns of FTSE/ JSE ALSI returns from 20 May 2005 to 31 May 2016, and the results showed that the APARCH 
model with PIDV and GPD for the short position and stable distribution innovations in the long position are best when dealing with the return series. The suitability of the APARCH $(1,1)$ model together with heavy-tailed distributions was suggested by Chifurira and Chinhamu (2019) for FTSE/JSE ALSI returns. It was noted that the volatility phenomenon and asymmetry were explained by the APARCH framework, and the heavy-tailed distributions account for the fat tails in returns. APARCH(1,1) with GPD or PIVD innovations have proven to be robust models for estimating VaR.

Dwarika et al. (2021) studied the volatility dynamics and the risk-return relationship in South Africa using a GARCH approach where FTSE/JSE All-Share Index returns were analyzed from 2009 to 2019. Various GARCH models were employed, and results revealed consistent volatility and a positive risk relationship in the South African market. Furthermore, this study suggests that volatility of the financial return series could be captured by the EGARCH $(1,1)$ model, however, the model failed to account for the asymmetry.

There is limited research on modelling South African data - JSE indices and the USD/South African (ZAR) exchange rate to GARCH-type, GPD and stable distributions (SD) to the best of our literature knowledge. Therefore, this study investigates the FTSE/JSE All-Share Index (FTSE/JSE ALSI), FTSE/JSE Banks Index, FTSE/JSE Mining Index, and the United States of American Dollar to the South African Rand exchange rate (USD/ZAR exchange rate) with the goal of attaining robust VaR models for financial returns. Using a GARCH framework, the stylized facts associated with financial returns such as heavy tails, asymmetry, leverage effect and volatility clustering are assessed through the fitting of suitable generalized Pareto distribution (GPD) and stable distribution (SD). The estimated VaR values are backtested to evaluate each model's robustness using the Kupiec likelihood ratio tests.

\section{METHOD}

This section presents the background theory on the GARCH-type models combined with GPD and SDs. VaR and backtesting procedures are also discussed.

\subsection{GARCH $(1,1)$}

The GARCH $(1,1)$ model presented by Bollerslev (1986) is considered a parsimonious model of conditional variance that fits many economic time series (Embrechts et al., 1999).

The GARCH $(1,1)$ model is defined as follows:

$$
\begin{aligned}
& \sigma_{x}^{2}=\alpha_{0}+\alpha_{1} \alpha_{x-1}^{2}+\beta_{1} \sigma_{x-1}^{2}, \\
& a_{x}=\sigma_{x} \varepsilon_{x},
\end{aligned}
$$

where $\varepsilon_{x} \sim N(0.1), \alpha_{0}>0, \beta_{1}>0$ and $\alpha_{1}+\beta_{1}<1$, and the next variance forecast period is a mix of previous period forecasts and the previous period's squared returns. $\alpha$ shows short-run persistence of shocks, and $\beta_{1}$ suggests long-run persistence of shocks. A disadvantage of the GARCH $(1,1)$ model is the symmetric nature of the model.

To consider asymmetry in the return series, extensions of the GARCH model are suggested to account for the weaknesses of the GARCH $(1,1)$ model. The EGARCH (Exponential GARCH) and other asymmetric GARCH-type models are applied to capture the stylized characteristics of financial data. $\sigma_{x}^{2}=\alpha_{0}+\alpha_{1} \alpha_{x-1}^{2}+\beta_{1} \sigma_{x-1}^{2}$,

\section{2. $\operatorname{EGARCH}(p, q)$ model}

The EGARCH model is defined in the study by Nelson (1991):

$$
\begin{aligned}
& \log \sigma_{x}^{2}=\alpha_{0}+ \\
& +\sum_{i=1}^{p} \alpha_{i}\left(\varphi Z_{x-i}+\gamma\left[\left|Z_{x-i}\right|-E\left|Z_{x-1}\right|\right]\right)+ \\
& +\sum_{j=1}^{q} \beta_{j} \log \sigma_{x-j}^{2}
\end{aligned}
$$

where $\alpha_{x}=\sigma_{x} \varepsilon_{x}$ and $\varepsilon_{x} \sim N(0.1), \alpha_{0}, \alpha_{i}, \beta_{j}, \phi$ and $\gamma \in$.

To guarantee the conditional variances are positive, there are no constraints placed on the $\alpha_{i}$ and $\beta$ p parameters unlike the GARCH $(p, q)$ model. $\operatorname{EGARCH}(p, q)$ models are favored when the negative and positive shocks of the same magnitude have no equal contributing effect to volatility.

Volatility in $\operatorname{EGARCH}(p, q)$ models is calculated by $\sigma_{x}^{2}$, the conditional variance, which is also the 
explicit multiplier of lagged innovations. However, with standard $\operatorname{GARCH}(p, q)$ models volatility is calculated by the summation of lagged error terms $\varepsilon_{x}$. $\operatorname{EGARCH}(p, q)$ model volatility responds differently to good and bad news. The same applies to the intensity and covariance-stationary parameters, as well as $Z_{x}$.

In this study, the Maximum Likelihood method is used to estimate $\operatorname{GARCH}(p, q)$ parameters.

\subsection{Heavy-tailed distributions}

This section describes the Generalized Pareto Distribution and Nolan's $S_{0}$-parameterization univariate stable distribution.

\subsubsection{The Generalized Pareto Distribution (GPD)}

The two-parameter Generalized Pareto Distribution (GPD), with the shape parameter $\xi$ and scale parameter $\beta$, is interpreted by Tsay (2013), proposed from Pickands (1975), as:

$$
G_{\xi \beta}(y)=\left\{\begin{array}{l}
1-\left(1+\frac{\xi y}{\beta}\right)^{-1 / \xi} \text { if } \xi \neq 0 \\
1-\exp \left(-\frac{y}{\beta}\right) \text { if } \xi=0
\end{array},\right.
$$

where $y>0$ when $\xi \geq 0,0 \leq y \leq-\beta / \xi$, when $\xi<0$ and $\beta>0$.

\subsubsection{Excess distribution}

Excess function $F_{u}$ for random variable $Y$, above a threshold $u$, is defined as:

$$
F_{u}(y)=P(Y-u \leq y \mid Y>u),
$$

where the size of exceedances over $u$ is represented by $y$. Additionally, if $F$ is denoted as distribution of $Y$, then:

$$
F_{u}(y)=\frac{F(y+u)-F(u)}{1-F(u)} .
$$

Balkema and De Haan (1974) and Pickands (1975), identified by a fundamental theorem in Extreme Value Theory, detect asymptotic properties of exceedances with GPD.
The peaks-over-threshold (POT) method is used to estimate the threshold of the GPD (Embrechts et al., 1997). In this paper, the maximum likelihood estimation method is used to determine GPD parameters.

\subsection{Univariate stable distributions}

Stable laws were introduced by the groundbreaking work of Levy (1925), and stable distributions are a four-parameter family of models that generalize the normal distribution based on stable laws. Stable distributions are described by parameters, namely $\alpha, \beta, \gamma$, and $\sigma$.

Various parameterizations are used to define stable laws. The notation $S(\alpha, \beta, \gamma, \sigma ; \mathrm{k})$ is used to describe the class of stable laws. The $\alpha, \beta, \gamma$, and $\sigma$ parameters are unknown and should be estimated. The integer $k$ distinguishes between the different parameterizations (Nolan, 2013).

Nolan (2013) describes the $S_{0}$-parameterization as follows:

A random variable $Y$ is $S(\alpha, \beta, \gamma, \sigma ; 0)$ if

$$
Y=\left\{\begin{array}{cc}
\gamma\left(Z-\beta \tan \frac{\pi \alpha}{2}\right)+\delta, & \alpha \neq 1 \\
\gamma Z+\delta, & \alpha=1
\end{array} .\right.
$$

where $Z \equiv Z(\alpha, \beta)$.

Nolan (2013) recommends using the $S_{0}$ - parameterization for statistical inferences and numerical purposes, since it has the simplest form for the characteristic function that is continuous in all four parameters. Nolan (2013) suggested that the maximum likelihood method is the most frequently used one to estimate stable parameters. In this study, stable parameters are estimated using the maximum likelihood method, and thereafter the Anderson-Darling goodness-of-fit test is applied to test the suitability of the fitted univariate stable models.

\subsection{Value-at-Risk}

Capital requirements of financial institutions are based on VaR estimates. VaR is a risk manage- 
ment tool that has become a benchmark for measuring market risks. The main goal of estimating $\mathrm{VaR}$ is to assess the largest possible loss for a portfolio over a certain period of time. The quantile of a distribution is used to estimate the VaR values. For a random variable $Y$, the VaR estimate at given probability $p$ is defined as the $p$-th quantile of $F$, that is:

$$
\operatorname{VaR}_{p}=F^{-1}(1-p)
$$

where $F^{-1}$ is the quantile function.

To examine the effectiveness and adequacy of $\mathrm{VaR}$, various backtesting procedures are utilized. Formal conclusions on model robustness can be obtained using the Kupiec likelihood ratio (Kupiec, 1995).

In this study, the Kupiec likelihood ratio test evaluates model robustness. According to the Kupiec likelihood ratio test, a good model should have its proportion of violations of VaR estimates close to the corresponding tail probability $\alpha$ (Kupiec, 1995).

The next section dives into the data exploration and empirical analyses.

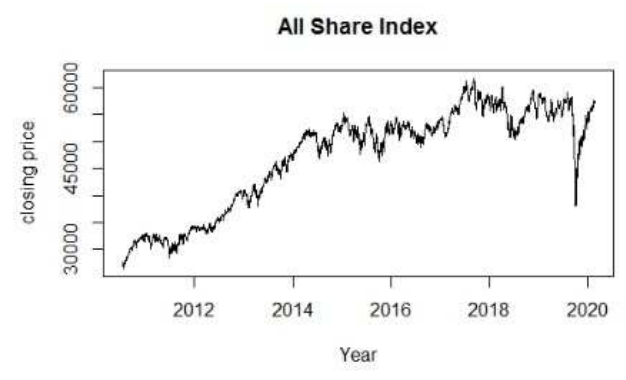

\section{DATA EXPLORATION}

In this section, the characteristics of the FTSE/ JSE financial stock indices and the USD/ZAR exchange rate are described, thereafter, robust VaR models are selected for each return series. This study investigates the performance of GARCH models with Generalized Pareto distribution (GPD) and stable distributions (SD) with the estimation and forecasting of VaR within the South African financial industry.

This study has data sets that consist of the daily closing prices of FTSE/JSE ALSI, FTSE/JSE Banks Index, FTSE/JSE Mining Index and USD/ZAR exchange rate prices obtained from McGregor BFA and recorded over the period from August 13, 2010 to August 14, 2020. The return series for each index is calculated as the first backward differences of the index values' natural logarithm. For day $t$, the daily $\log$ return $r_{t}$ is defined as

$$
r_{t}=\ln \left(P_{t}\right)-\ln \left(P_{t-1}\right)
$$

where $P_{t}$ is the price at day $t$. Time series plots for both daily closing prices and returns are shown in Figures 1 to 4 .

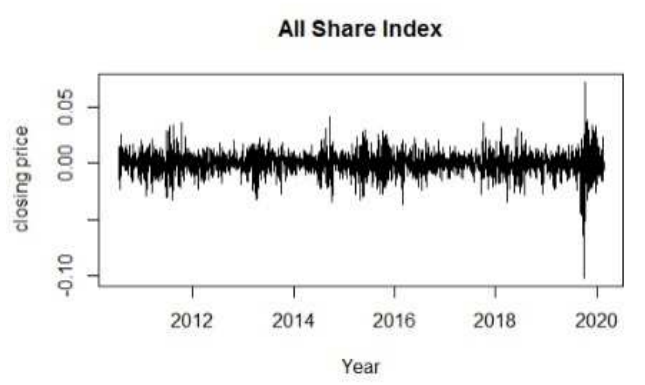

Figure 1. Time series plot of FTSE/JSE All Share Index prices (left) and one-day returns (right)
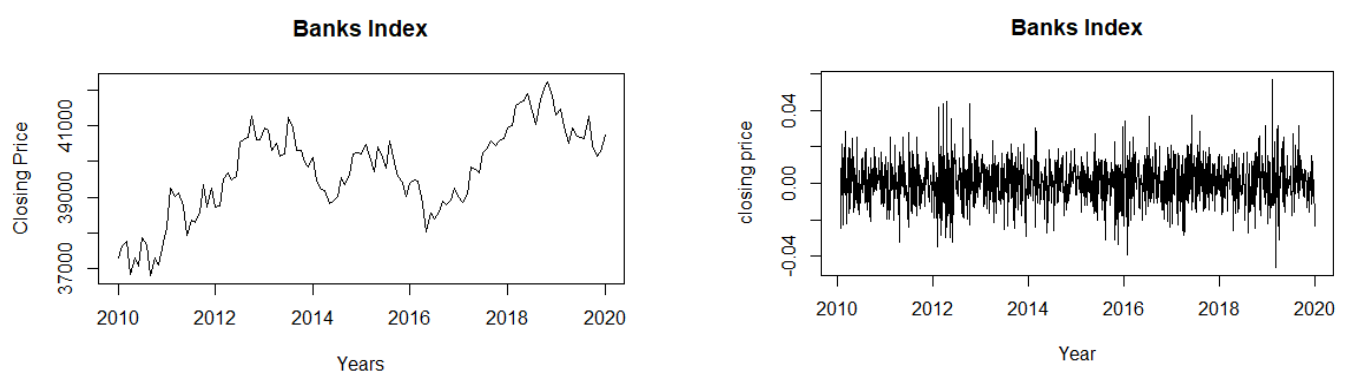

Figure 2. Time series plot of FTSE/JSE Banks Index prices (left) and one-day returns (right) 

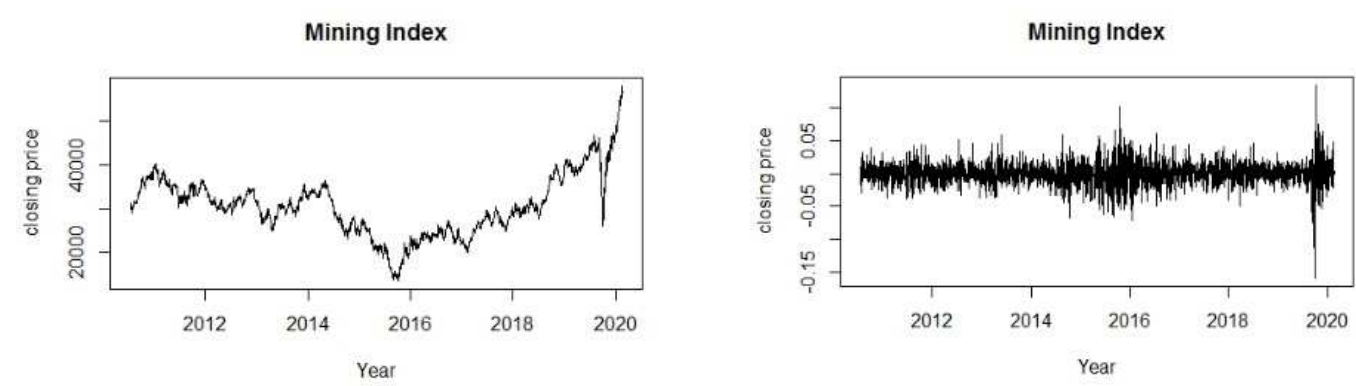

Figure 3. Time series plot of FTSE/JSE Mining Index prices (left) and one-day returns (right)
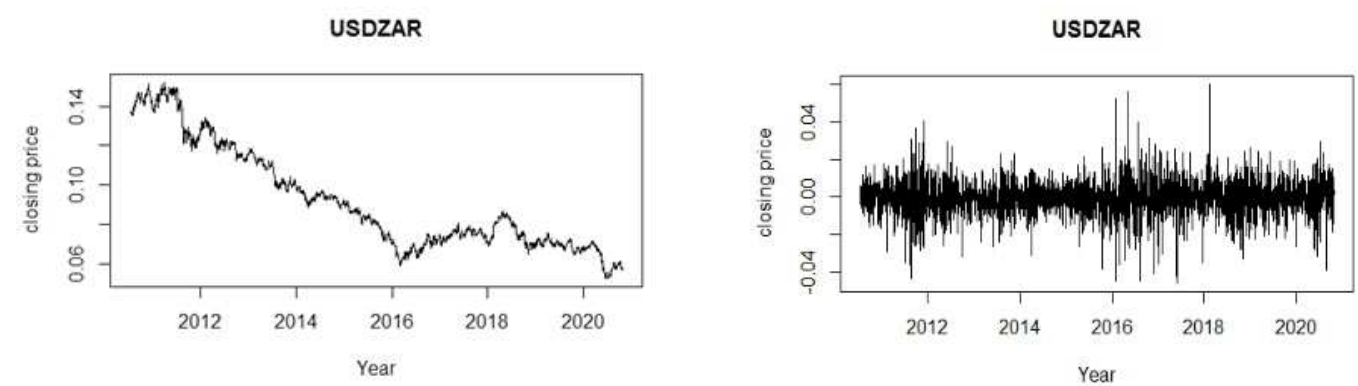

Figure 4. Time series plot of USD/ZAR exchange rate prices (left) and one-day returns (right)

In Figures 1-4, the plots seem to show various trends in mean and variance over time, indicating non-stationarity. The log returns are stationary as the mean hovers around 0 , however, the variance varies over time, indicating heteroscedasticity and volatility clustering, which is likely when dealing with financial data. Isolated extreme returns caused by shocks to financial markets are visible, such as the 2015 stock market crash and the 20192020 global COVID-19 pandemic.

Descriptive statistics for the daily closing prices of the financial stock indices returns and USD/ZAR exchange rate returns are shown in Panel A of

Table 1. Descriptive statistics of financial stock market indices and exchange rate price returns

\begin{tabular}{|c|c|c|c|c|}
\hline \multicolumn{5}{|c|}{ Panel A } \\
\hline Basic statistics & FTSE/JSE ALSI & FTSE/JSE Banks Index & FTSE/JSE Mining Index & USD/ZAR exchange rate \\
\hline $\begin{array}{l}\text { No. of } \\
\text { observations }\end{array}$ & 2,499.00 & $2,499.00$ & $2,499.00$ & $2,675.00$ \\
\hline Minimum & -0.1023 & -2.3021 & -0.1589 & -0.0460 \\
\hline Maximum & 0.0726 & 0.0991 & 0.1346 & 0.0603 \\
\hline Mean & 0.0003 & -0.0008 & 0.0002 & -0.0003 \\
\hline Median & 0.0006 & 0.0005 & 0.0003 & 0.0000 \\
\hline Skewness & -0.7310 & -41.0875 & -0.1605 & -0.1671 \\
\hline Excess kurtosis & 8.8822 & 1919.8771 & 6.0443 & 2.7766 \\
\hline
\end{tabular}

Panel B

Testing for normality, autocorrelation and heteroscedasticity

\begin{tabular}{|c|c|c|c|c|c|c|c|c|}
\hline Test & Statistic & $p$-value & Statistic & $p$-value & Statistic & $p$-value & Statistic & $p$-value \\
\hline Jarque-Bera & $8,455.2667$ & $<0.0001$ & $385,117.132$ & $<0.0001$ & $3,823.9300$ & $<0.0001$ & 874.3992 & $<0.0001$ \\
\hline Ljung Box & 67.2900 & $<0.0001$ & 7.0024 & 0.9967 & 47.6200 & 0.0005 & 11.7751 & 0.9236 \\
\hline ARCH LM Test & 936.0966 & $<0.0001$ & 0.0000 & 0.9900 & 50.0300 & 0.00 & 15.4100 & 0.0000 \\
\hline
\end{tabular}

Testing for unit root and stationarity

\begin{tabular}{|c|c|c|c|c|c|c|c|c|}
\hline Unit root test & Statistic & $p$-value & Statistic & $p$-value & Statistic & $p$-value & Statistic & $p$-value \\
\hline ADF Test & -13.6259 & 0.01 & -12.9576 & 0.01 & -13.5509 & 0.01 & -14.7402 & $<0.0001$ \\
\hline PP Test & $-2,586.908$ & 0.01 & $-2,548.2810$ & 0.01 & $-2,430.247$ & 0.01 & $-2,688.0280$ & $<0.0001$ \\
\hline KPSS Test & 0.1303 & 0.10 & 0.0914 & 0.10 & 0.2394 & 0.10 & 0.0431 & 0.1000 \\
\hline
\end{tabular}


Table 1. Positive averages for FTSE/JSE ALSI and FTSE/JSE Mining Index returns indicate a slight increasing trend over time, whereas the negative averages for the FTSE/JSE Banks Index and USD/ ZAR exchange rate returns indicate a slight decreasing trend over time for the return series.

Tests for normality, autocorrelation and heteroscedasticity are shown in Panel B. The null hypothesis of normality for the Jarque-Bera test is rejected at the $5 \%$ level of significance for all returns. This implies that the use of heavy-tailed models should be considered when analyzing the returns series.

The significant $p$-values of the Ljung-Box test for FTSE/JSE ALSI and the FTSE/JSE Mining Index returns suggest the failure to reject the null hypothesis of no autocorrelation. The fitting of a statistical distribution usually assumes homoscedasticity and no autocorrelation.

Results for the unit root and stationary tests are shown in Panel C. At a 5\% level of significance, the null hypothesis of a unit root is rejected, and it can be concluded that all return series are stationary. The KPSS test showed that all returns are stationary, since all $\mathrm{p}$-values are 0.1 , which is greater than 0.05 , therefore null hypothesis of stationarity is accepted.

\section{RESULTS}

In this study, the best $\operatorname{GARCH}(p, q)$-type model that adequately captures volatility clustering in the return series is investigated. First, the GARCH $(1,1)$ model with normal innovations using the Maximum Likelihood (ML) method to the return series is fitted. The ML parameter estimates and their corresponding $p$-values of the $\mathrm{t}$-statistics for the GARCH $(1,1)$ model are shown in Table 2 Panel A. In Panel B of Table 2, the p-values of Ljung-Box and the ARCH-LM test statistics are reported.

From Table 2, the coefficient of $\hat{\beta}_{1}$ for the stock returns under investigation is significant ( $p$-value $>0.05$ ). This relates to the measurement of volatility persistence, which indicates that the period of high volatility is followed by periods of low volatility, and the converse is also true. The $p$-values of the Ljung-Box are greater than 0.05 , therefore, at a $5 \%$ level of significance, there is evidence to reject the null hypothesis of serial correlation as the GARCH $(1,1)$ model with normal innovations indicates that each financial stock returns are not serially correlated. The ARCH LM test confirms ARCH effects of each return series.

The sign bias test is implemented in Table 3 to test if returns can be modelled by asymmetric distribution.

Table 2. ML parameter estimates for GARCH $(1,1)$ model with normal innovations and corresponding goodness-of-fit statistics for Financial stock returns

\begin{tabular}{|c|c|c|c|c|}
\hline Parameter estimates & FTSE/JSE ALSI & FTSE/JSE Banks Index & $\begin{array}{l}\text { FTSE/JSE Mining } \\
\text { Index }\end{array}$ & $\begin{array}{l}\text { USD/ZAR exchange } \\
\text { rate }\end{array}$ \\
\hline \multicolumn{5}{|c|}{$\begin{array}{l}\text { Panel A } \\
\text { Financial stock returns }\end{array}$} \\
\hline$\widehat{\alpha_{0}}$ & 0.0000 & 0.0000 & 0.0000 & 0.0000 \\
\hline$\widehat{\alpha_{1}}$ & 0.0884 & 0.1479 & 0.0583 & 0.0442 \\
\hline$\widehat{\beta}_{1}$ & 0.8891 & 0.7691 & 0.9289 & 0.9447 \\
\hline \multicolumn{5}{|c|}{$\begin{array}{c}\text { Panel B } \\
p \text {-values of the corresponding to the parameter estimates or test statistics }\end{array}$} \\
\hline$\widehat{\alpha_{0}}$ & 0.0466 & 0.0000 & 0.0549 & 0.1417 \\
\hline$\widehat{\alpha_{1}}$ & 0.0000 & 0.0000 & 0.0000 & 0.0000 \\
\hline$\widehat{\beta}_{1}$ & 0.0000 & 0.0000 & 0.0000 & 0.0000 \\
\hline Ljung-Box & 0.1308 & 0.8106 & 0.1455 & 0.2262 \\
\hline ARCH-LM & 0.5060 & 0.9833 & 0.1892 & 0.1726 \\
\hline
\end{tabular}


Table 3. Sign bias test of return series

\begin{tabular}{|c|c|c|c|c|}
\hline Sign-bias estimates & FTSE/JSE ALSI & $\begin{array}{l}\text { FTSE/JSE Banks } \\
\text { Index }\end{array}$ & $\begin{array}{l}\text { FTSE/JSE Mining } \\
\text { Index }\end{array}$ & $\begin{array}{l}\text { USD/ZAR exchange } \\
\text { rate }\end{array}$ \\
\hline \multicolumn{5}{|c|}{$\begin{array}{c}\text { Panel A } \\
\text { Financial stock returns }\end{array}$} \\
\hline Sign-bias & 1.5437 & 1.1174 & 0.7800 & 0.5062 \\
\hline Negative sign-bias & 0.1009 & 0.0020 & 1.3182 & 0.6277 \\
\hline Positive sign-bias & 2.5654 & 0.5379 & 1.1302 & 1.6774 \\
\hline Joint effect & 24.3508 & 1.2914 & 4.0531 & 4.1492 \\
\hline \multicolumn{5}{|c|}{$\begin{array}{c}\text { Panel B } \\
p \text {-values of the corresponding to Sign-bias estimates }\end{array}$} \\
\hline Sign-bias & $<0.0001$ & 0.2639 & 0.4355 & 0.6127 \\
\hline Negative sign-bias & $<0.0001$ & 0.9984 & 0.1876 & 0.5303 \\
\hline Positive sign-bias & $<0.0001$ & 0.5907 & 0.2583 & 0.0936 \\
\hline Joint effect & $<0.0001$ & 0.7312 & 0.2558 & 0.2458 \\
\hline
\end{tabular}

The sign bias test shows $p$-values greater than 0.05 , except for the FTSE/JSE ALSI. The negative and positive sign bias $p$-values greater than 0.05 imply that there were significant positive and negative reaction shocks to the returns, with an exception of FTSE/JSE ALSI. The joint effect was significant for ALSI, implying that returns are asymmetrical. Table 3 shows that ALSI returns are asymmetric and best captured by asymmetric GARCH-type models.
Table 4 shows the results of fitting an $\operatorname{EGARCH}(1,1)$, $\operatorname{APARCH}(1,1)$, and $\operatorname{TGARCH}(1,1)$, models to the FTSE/JSE ALSI returns.

Table 4 presents the results of fitting the EGARCH $(1,1)$, APRACH $(1,1)$ and TGARCH $(1,1)$ models to the FTSE/JSE ALSI returns. Based on AIC and BIC values, a GARCH-type model is the best asymmetric model for a set of returns, while the $\operatorname{EGARCH}(1,1)$ model is for the FTSE/JSE ALSI returns.

Table 4. ML parameter estimates for asymmetric GARCH-type models with normal innovations on ALSI returns

\begin{tabular}{|c|c|c|c|}
\hline \multirow{2}{*}{ Parameter estimates } & \multicolumn{3}{|c|}{ Asymmetric GARCH-type model } \\
\hline & $\operatorname{EGARCH}(1,1)$ & $\operatorname{APARCH}(1,1)$ & $\operatorname{TGARCH}(1,1)$ \\
\hline \multicolumn{4}{|c|}{$\begin{array}{c}\text { Panel A } \\
\text { FTSE/JSE ALSI returns }\end{array}$} \\
\hline$\widehat{\alpha_{0}}$ & -0.2015 & 0.0002 & 0.0000 \\
\hline$\widehat{\alpha_{1}}$ & -0.1342 & 0.0682 & 0.0000 \\
\hline$\widehat{\beta_{1}}$ & 0.9783 & 0.9244 & 0.9070 \\
\hline$\hat{\gamma}_{1}$ & 0.0863 & 1.0000 & - \\
\hline$\hat{\delta}_{1}$ & - & 1.0000 & - \\
\hline$\hat{\eta}_{11}$ & - & - & 0.1397 \\
\hline \multicolumn{4}{|c|}{$\begin{array}{c}\text { Panel B } \\
p \text {-values of the corresponding to the parameter estimates or AIC/BIC }\end{array}$} \\
\hline$\widehat{\alpha_{0}}$ & 0.0000 & 0.0000 & 0.0025 \\
\hline$\widehat{\alpha_{1}}$ & 0.0000 & 0.0000 & 0.0000 \\
\hline$\widehat{\beta_{1}}$ & 0.0000 & 0.0000 & 0.0000 \\
\hline$\hat{\gamma}_{1}$ & 0.0000 & 0.0000 & - \\
\hline$\hat{\delta}_{1}$ & - & 0.0000 & - \\
\hline$\hat{\eta}_{11}$ & - & - & 0.0000 \\
\hline AIC & -6.5637 & -6.5603 & -6.5594 \\
\hline $\mathrm{BIC}$ & -6.5520 & -6.5486 & -6.5478 \\
\hline
\end{tabular}




\subsection{Fitting the hybrid-GARCH-type- GPD models}

The standardized residuals from the GARCHtype model were extracted, and the GPD was fitted using the ML estimation procedure. The new model is a hybrid model of a GARCH-type model and GPD, here referred to as a hybridGARCH-type-GPD model. The GPD model is fitted to the upper (gains) and lower tails (loses). To select thresholds, a mean residual life plot and parameter stability plot will be utilized. The Pareto Quantile plot will also be used to confirm the threshold.
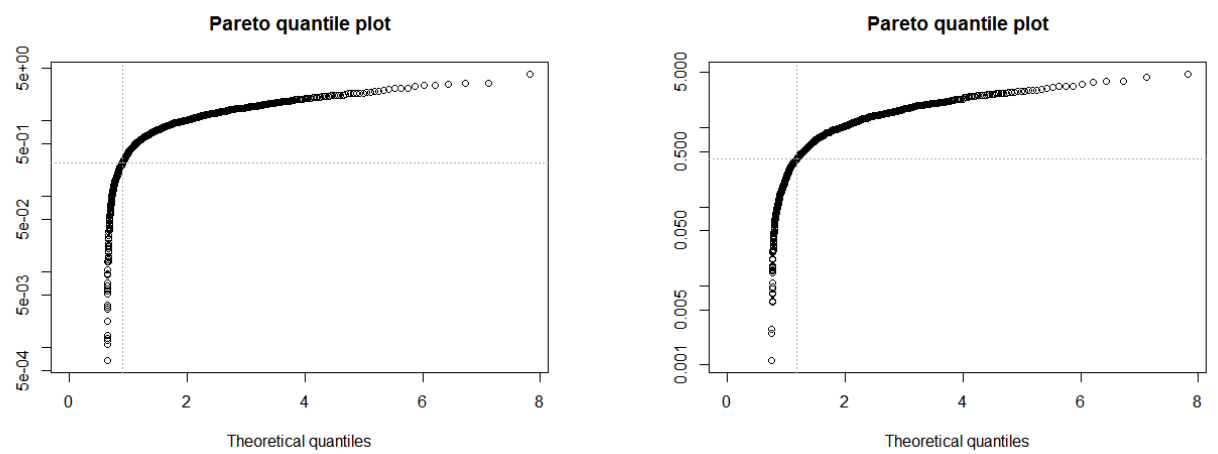

Figure 5. FTSE/JSE ALSI Returns Pareto quantile plot of positive (left) and negative (right) standardized residuals
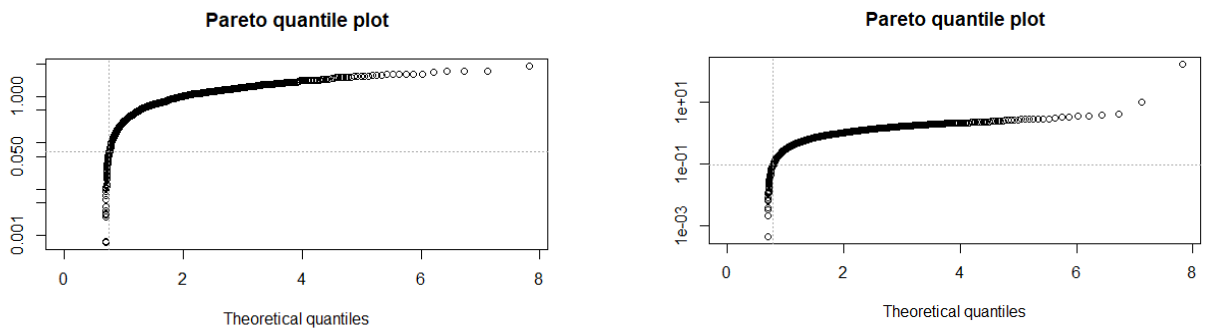

Figure 6. FTSE/JSE Banks Index Returns Pareto quantile plot of positive (left) and negative (right) standardized residuals
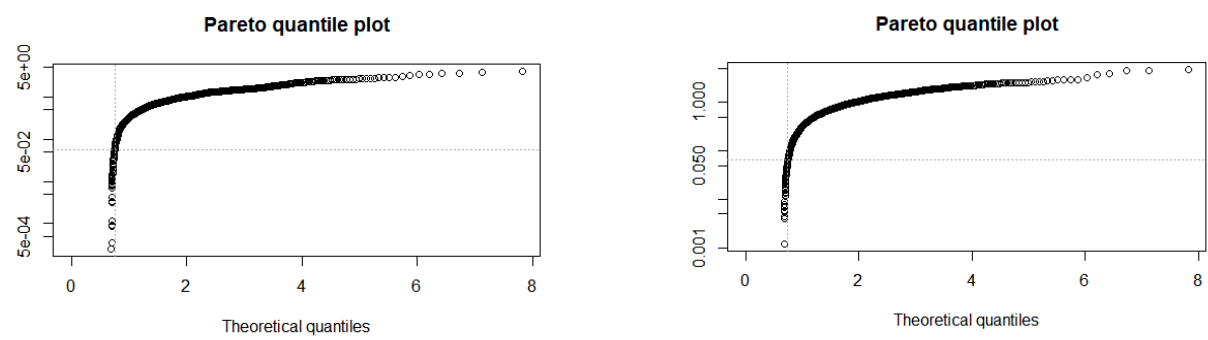

Figure 7. FTSE/JSE Mining Index Returns Pareto quantile plot of positive (left) and negative (right) standardized residuals
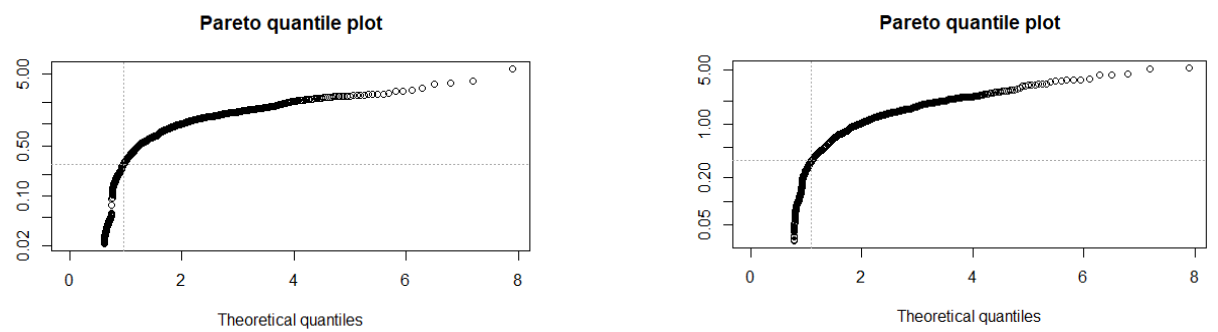

Figure 8. USD/ZAR Exchange Rate Returns Pareto quantile plot of positive (left) and negative (right) standardized residuals 
Table 5. ML parameter estimates of hybrid GARCH-type-GPD model

\begin{tabular}{|c|c|c|c|c|c|c|c|c|}
\hline Returns & FTSE/J & ALSI & FTSE/JSE & ks index & FTSE/JSE & ing index & USD/ZAR & ange rate \\
\hline Tail & Upper & Lower & Upper & Lower & Upper & Lower & Upper & Lower \\
\hline Threshold (u) & 1.32 & 1.5 & 1.06 & 1.09 & 1.06 & 1.06 & 1.31 & 1.4 \\
\hline $\begin{array}{l}\text { Number of } \\
\text { exceedances }\end{array}$ & 188 & 172 & 313 & 313 & 306 & M334 & 200 & 211 \\
\hline$\hat{\varepsilon}$ & 0.4499 & 0.6640 & 0.5282 & 0.5019 & 0.5752 & 0.6278 & 0.4558 & 0.6064 \\
\hline $\operatorname{SE}(\hat{\varepsilon})$ & 0.0456 & 0.0699 & 0.0445 & 0.0371 & 0.0469 & 0.0448 & 0.0469 & 0.0630 \\
\hline$\hat{\sigma}$ & -0.0172 & -0.0687 & 0.0007 & 0.2584 & -0.0370 & -0.0491 & 0.0905 & 0.0649 \\
\hline $\operatorname{SE}(\hat{\sigma})$ & 0.0706 & 0.0728 & 0.0624 & 0.0497 & 0.0582 & 0.0460 & 0.0750 & 0.0779 \\
\hline
\end{tabular}

Figure 9 and Figure 10 below show the respective GPD model diagnostic plot for the positive and negative FTSE/JSE ALSI residuals.

\subsection{ALSI GPD model diagnostic plots}

The PP and QQ plot do not seem to show any major divergences from the straight lines, and the return level and density plots show that positive and negative standardized residuals follow a GPD in both the lower and upper tails for the FTSE/JSE All Share Index. Similar deductions are made for all return series observed in this study.

\subsection{Fitting the hybrid GARCH-type-SD models}

Standardized residuals of the best GARCH-type model are extracted, and stable parameters are estimated under Nolan's $S_{0}$ - parameterization using maximum likelihood estimation resulting in a GARCH-type model combined with SD governing the innovations. This model is referred to as the hybrid GARCH-type-SD model. Table 6 reports the ML parameter estimates of SD fitted to the standardized residuals extracted from the suitable GARCH-type model.

Table 6. ML parameter estimates of the hybrid GARCH-type-SD model

\begin{tabular}{|c|c|c|c|c|}
\hline \multirow{2}{*}{ Parameter estimates } & \multicolumn{4}{|c|}{ Financial stock returns } \\
\hline & FTSE/JSE ALSI & FTSE/JSE Banks Index & FTSE/JSE Mining Index & USD/ZAR exchange rate \\
\hline$\hat{\alpha}$ & 1.9012 & 1.9052 & 1.9149 & 1.8474 \\
\hline$\hat{\beta}$ & -0.8719 & -0.1299 & -0.1567 & -0.5224 \\
\hline$\hat{\gamma}$ & 0.6689 & 0.6586 & 0.6714 & 0.6396 \\
\hline$\hat{\delta}$ & 0.0834 & -0.0102 & -0.0028 & 0.0634 \\
\hline $\begin{array}{l}\text { AD Test } \\
\text { ( } p \text {-value) }\end{array}$ & $\begin{array}{c}0.8937 \\
(0.4181)\end{array}$ & $\begin{array}{c}-^{*} \\
(<0.0001)\end{array}$ & $\begin{array}{c}0.5147 \\
(0.7319)\end{array}$ & $\begin{array}{c}1.5819 \\
(0.1581)\end{array}$ \\
\hline
\end{tabular}

Note: * No AD statistic available for FTSE/JSE Banks Index.
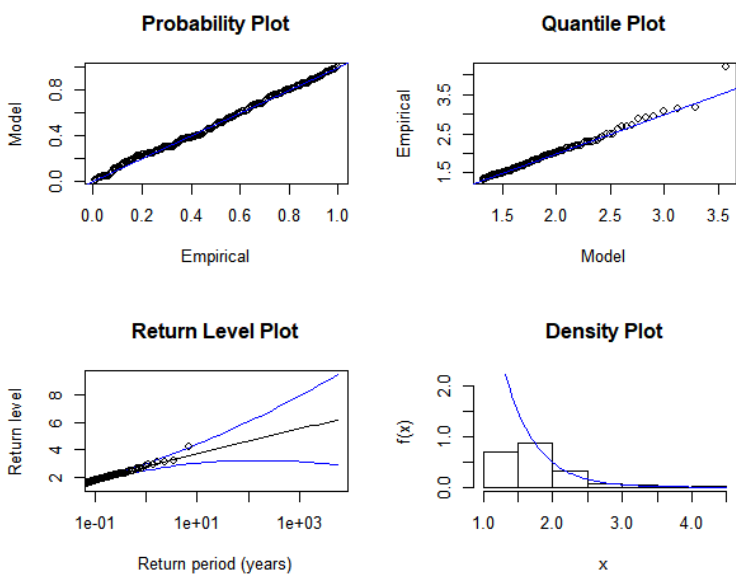

Figure 9. GPD positive ALSI residuals
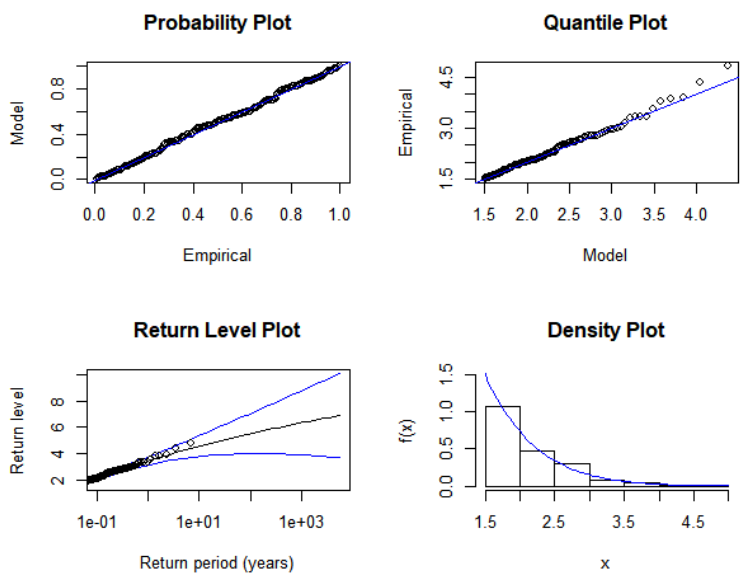

Figure 10. GPD negative ALSI residuals 


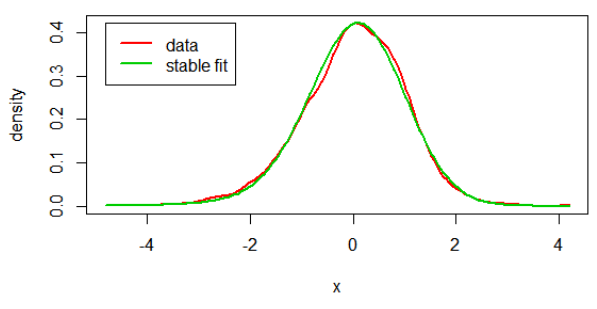

a) FTSE/JSE ALSI

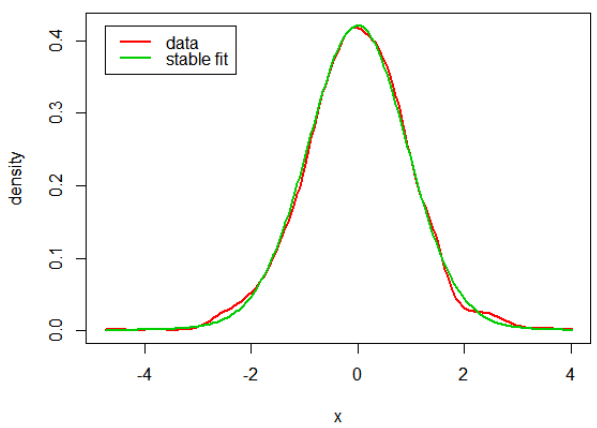

c) FTSE/JSE Mining Index

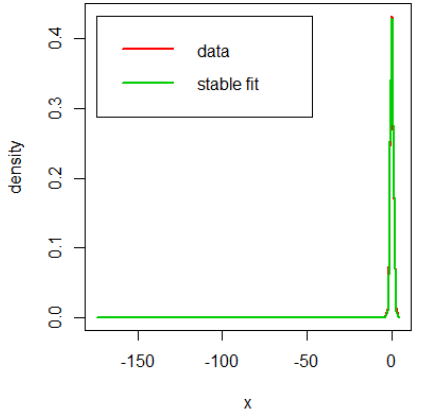

b) FTSE/JSE Banks Index

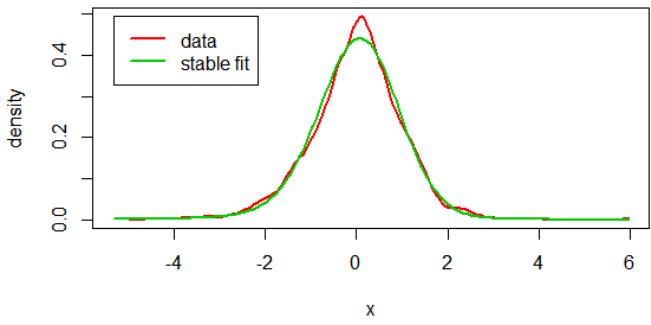

d) FTSE/JSE USD/ZAR

Figure 11. Stable density plots of return series

Stable density plots in Figure 11 indicate that the estimated univariate $S_{0}(\alpha, \beta, \gamma, \delta)$ model is adequate in describing the residuals extracted through the GARCH-type model.

\subsection{VaR and backtesting}

$\mathrm{VaR}$ values are calculated at different levels. Table 7 shows VaR estimates at different VaR levels of the suitable hybrid GARCH-GPD and GARCHSD models of the financial market and USD/ZAR exchange rate returns.
Table 7 shows that the VaR models resulting from VaR estimates are within the same ranges for short and long positions. The VaR estimates from the fitted hybrid GARCH-type models are backtested using the Kupiec likelihood ration test. The $p$-values of the Kupiec likelihood ration test at different VaR levels are summarized in Table 8.

Table 8 shows the $p$-values of the Kupiec likelihood ration test, the fitted GARCH-GPD and GARCHSD models are well suited to the return series observed in this study at almost all VaR levels, since

Table 7. VaR estimates of the financial market indices and exchange rate price returns using fitted hybrid GARCH-GPD and GARCH-SD model

\begin{tabular}{|c|c|c|c|c|c|}
\hline \multirow{3}{*}{ Financial stock returns } & \multirow{3}{*}{ Hybrid Model } & \multicolumn{4}{|c|}{ VaR estimates at different levels } \\
\hline & & \multicolumn{2}{|c|}{ Short position } & \multicolumn{2}{|c|}{ Long position } \\
\hline & & $2.5 \%$ & $5 \%$ & $95 \%$ & $97.5 \%$ \\
\hline \multirow{2}{*}{ FTSE/JSE ALSI } & $\operatorname{EGARCH}(1,1)-G P D$ & 1.8110 & 1.5032 & 1.7099 & 2.1495 \\
\hline & $\operatorname{EGARCH}(1,1)-\mathrm{SD}$ & -2.0928 & -1.6655 & 1.5604 & 1.8478 \\
\hline \multirow{2}{*}{ FTSE/JSE Banks Index } & GARCH $(1,1)-G P D$ & 1.9116 & 1.5451 & 1.61010 & 2.0931 \\
\hline & $\mathrm{GARCH}(1,1)-\mathrm{SD}$ & -1.9652 & -1.6100 & 1.5513 & 1.8868 \\
\hline \multirow{2}{*}{ FTSE/JSE Mining Index } & GARCH $(1,1)-G P D$ & 1.9476 & 1.5668 & 1.6627 & 2.0703 \\
\hline & $\operatorname{GARCH}(1,1)-S D$ & -1.9859 & -1.6295 & 1.5818 & 1.9170 \\
\hline \multirow{2}{*}{ USD/ZAR exchange rate } & GARCH $(1,1)-G P D$ & 1.8350 & 1.4968 & 1.6806 & 2.1234 \\
\hline & GARCH $(1,1)-S D$ & -2.0848 & -1.6355 & 1.5124 & 1.8219 \\
\hline
\end{tabular}


Table 8. $p$-values of the Kupiec likelihood ratio test for financial indices and exchange rate returns

\begin{tabular}{|c|c|c|c|c|c|}
\hline \multirow{3}{*}{ Financial stock returns } & \multirow{3}{*}{ Hybrid Model } & \multicolumn{4}{|c|}{$p$-values of the Kupiec likelihood ratio test } \\
\hline & & \multicolumn{2}{|c|}{ Short position } & \multicolumn{2}{|c|}{ Long position } \\
\hline & & $2.5 \%$ & $5 \%$ & $95 \%$ & $97.5 \%$ \\
\hline \multirow{2}{*}{ FTSE/JSE ALSI } & $\operatorname{EGARCH}(1,1)-G P D$ & 0.7479 & 0.6851 & 0.9304 & 0.5618 \\
\hline & $\operatorname{EGARCH}(1,1)-\mathrm{SD}$ & 0.9464 & 0.5212 & 0.0480 & 0.4766 \\
\hline \multirow{2}{*}{ FTSE/JSE Banks Index } & GARCH(1,1)-GPD & 0.9514 & 0.5527 & 0.3170 & 0.3985 \\
\hline & $\mathrm{GARCH}(1,1)-\mathrm{SD}$ & 0.2849 & 0.3170 & 0.7156 & 0.5665 \\
\hline \multirow{2}{*}{ FTSE/JSE Mining Index } & GARCH(1,1)-GPD & 0.7496 & 0.3288 & 0.9963 & 0.5665 \\
\hline & $\mathrm{GARCH}(1,1)-\mathrm{SD}$ & 0.2849 & 0.5212 & 0.0600 & 0.9514 \\
\hline \multirow{2}{*}{ USD/ZAR exchange rate } & GARCH(1,1)-GPD & 0.8156 & 0.5356 & 0.9823 & 0.8895 \\
\hline & GARCH $(1,1)-S D$ & 0.4547 & 0.4685 & 0.6717 & 0.8156 \\
\hline
\end{tabular}

the observed $p$-values are greater than 0.05 . Hence, the null hypothesis of model adequacy is accepted. The GARCH-GPD model suggests model inadequacy for the $99 \%$ VaR level for the Banks Index returns, whereas the fitted GARCH-SD models show model inadequacy for the Mining Index returns at the $99 \%$ VaR, when considering a 5\% level of significance. However, with a $1 \%$ level of significance, the robustness of the fitted GARCH-SD models is highlighted at all VaR levels, whereas the fitted GARCH-GPD still displays model inadequacy at the $99 \% \mathrm{VaR}$ level. The most robust VaR model is summarized at each VaR level. Table 9 shows the most appropriate hybrid GARCH-type model selected at different VaR levels for the returns of the financial indices and USD/ZAR exchange rate returns.

It is clear from Table 9 that there is no hybrid model that outperforms another at all VaR levels for all financial stock returns. For FTSE/JSE ALSI, the EGARCH(1,1)-GPD model is the most robust VaR model at the $5 \%$ short position and at all long positions. For FTSE/JSE Banks index, GARCH $(1,1)$ $\mathrm{SD}$ is the robust model at all levels of the long position, and the GARCH(1,1)-GPD model is the robust model at all levels of the short position. For FTSE/JSE Mining index, the GARCH(1,1)-GPD is the best VaR model at the 2.5\% VaR level at short position and 5\% VaR level at long position. At the 5\% VaR level short position and 2.5\% VaR level at long position, the GARCH(1,1)-SD is the most appropriate VaR model for FTSE/JSE Mining index. The GARCH(1,1)-GPD model performs best at all $\mathrm{VaR}$ levels for USD/ZAR exchange rate returns.

\section{DISCUSSION}

Preliminary tests were conducted to investigate the nature of each return series and to highlight the stylized properties of financial data such as volatility clustering and heteroscedasticity. In this study, each FTSE/JSE indices and USD/ ZAR exchange rate showed leptokurtic behavior, stationarity and rejected the hypothesis of normality. Serial correlation is evident in the FTSE/JSE Banks Index and USD/ZAR exchange rate returns, which opposes the assumption of no serial correlation and heteroscedasticity when fitting a suitable statistical distribution. However, McNeil, et al (2015) showed that some financial return series exhibit serial correlation. Evidence for empirical properties of financial data with ARCH effects in reach return series implies the use of the GARCH-type framework

Table 9. Most appropriate hybrid GARCH-type model selected for financial indices and USD/ZAR exchange rate returns at different VaR levels

\begin{tabular}{|c|c|c|c|c|}
\hline \multirow{3}{*}{ Financial stock returns } & \multicolumn{4}{|c|}{ Selected hybrid GARCH-type models at different VaR levels } \\
\hline & \multicolumn{2}{|c|}{ Short position } & \multicolumn{2}{|c|}{ Long position } \\
\hline & $2.5 \%$ & $5 \%$ & $95 \%$ & $97.5 \%$ \\
\hline FTSE/JSE ALSI & $\operatorname{EGARCH}(1,1)-S D$ & $\operatorname{EGARCH}(1,1)-G P D$ & EGARCH(1,1)-GPD & EGARCH(1,1)-GPD \\
\hline FTSE/JSE Banks & GARCH(1,1)-GPD & GARCH(1,1)-GPD & GARCH(1,1)-SD & GARCH $(1,1)-S D$ \\
\hline FTSE/JSE Mining & GARCH $(1,1)-G P D$ & GARCH $(1,1)-S D$ & GARCH $(1,1)-G P D$ & $\mathrm{GARCH}(1,1)-\mathrm{SD}$ \\
\hline USD/ZAR Exchange rate & GARCH(1,1)-GPD & GARCH(1,1)-GPD & GARCH(1,1)-GPD & GARCH(1,1)-GPD \\
\hline
\end{tabular}


with heavy-tailed distributions Generalized Pareto Distribution (GPD) and Nolan's $\mathrm{S}_{0}$ parameterization stable distribution (SD).

The suitability of the $\mathrm{GARCH}(1,1)$ model for each return series is confirmed, except for FTSE/ JSE ALSI where asymmetric effects are present. $\operatorname{EGARCH}(1,1)$ was found to best capture volatility present in FTSE/JSE ALSI returns.

The GDP model fitted to the tail distribution has been shown to capture asymmetry in tails in line with McNeil and Frey (2000), which uses a conditional method for estimating tail innovations of a GARCH-type model using a heavy- tailed distributions recommended by extreme value theory (EVT).

The stable density plots and model diagnostics suggest a good fit of the residuals for each financial return series similar to Nolan (2003), thus suggesting a strong alternative to modelling the tail behavior of fitted GARCH-type models. The fitted GARCH-type SD model outperforms the fitted GARCH-type GPD model at various VaR levels using the Kupiec likelihood backtesting procedure, especially in the upper tail (gains) for the FTSE/JSE indices. Therefore, the robustness of a fitted hybrid GARCH-type SD model is highlighted when considering tail innovations of South African financial data.

\section{CONCLUSION}

This paper analyzes daily returns of four South African data sets, namely, FTSE/JSE ALSI, FTSE/JSE Banks index, FTSE/JSE Mining index and the USD/ZAR exchange rate. The GARCH(1,1) model was fitted to each return series, and the sign bias showed asymmetry for FTSE/JSE ALSI only. Thereafter, the GPD and Nolan's $S_{0}$-parameterization stable models were fitted to the best GARCH-type model residuals. Model diagnostics show that both the GARCH(1,1)-GPD and GARCH(1,1)-SD models provide a parsimonious fit to the South African financial data.

VaR estimates and VaR in-sample backtesting using the Kupiec likelihood ratio test emphasize the robustness of the fitted GARCH(1,1)-SD model in both long and short positions. Stable distributions are largely justified in finance, since they capture large fluctuations, as well as various other empirical properties, for example, heavy tails, asymmetry and volatility that are prevalent in financial data. Parties concerned with extreme losses such as risk analysts, insurers, policy makers, and risk-averse investors may benefit from the use of GARCH(1,1)-GPD and GARCH(1,1)-SD models as an alternative to modelling financial series. As further research, possible alternative criteria for evaluating and selecting a data tail-based model, such as the hybrid GARCH-type mixture model of GPD-Normal-SD, where GPD estimates VaR values in a short position and SD estimates VaR values in a long position jointly, are recommended.

\section{AUTHOR CONTRIBUTIONS}

Conceptualization: Kimera Naradh.

Formal analysis: Kimera Naradh, Knowledge Chinhamu, Retius Chifurira.

Investigation: Kimera Naradh.

Methodology: Kimera Naradh.

Software: Knowledge Chinhamu.

Supervision: Knowledge Chinhamu, Retius Chifurira.

Validation: Kimera Naradh, Retius Chifurira.

Writing - original draft: Kimera Naradh.

Writing - review \& editing: Knowledge Chinhamu, Retius Chifurira. 


\section{REFERENCES}

1. Ali, G. (2013). EGARCH, GJRGARCH, TGARCH, AVGARCH, NGARCH, IGARCH and APARCH models for pathogens at marine recreational sites. Journal of Statistical and Econometric Methods, 2(3), 57-73. Retrieved from https://www.scienpress.com/ Upload/JSEM/Vol\%202_3_6.pdf

2. Balkema, A. A., \& De Haan, L. (1974). Residual life time at great age. The Annals of Probability, 2(5), 792-804. https://doi.org/10.1214/ aop/1176996548

3. Bollerslev, T. (1986). Generalized autoregressive conditional heteroskedasticity. Journal of Econometrics, 31(3), 307-327. https://doi.org/10.1016/03044076(86)90063-1

4. Borak, S., Härdle, W., \& Weron, R. (2005). Stable distributions (SFB 649 Discussion Paper No. 2005-008). Berlin. Retrieved from http://prac.im.pwr.edu.pl/ hugo/ publ/SFB2005-008_Borak_Haerdle_Weron.pdf

5. Byström, H. N. (2005). Extreme value theory and extremely large electricity price changes. International Review of Economics \& Finance, 14(1), 41-55. https:// doi.org/10.1016/S1059. 0560(03)00032-7

6. Campbell, S. (2005). A review of backtesting and backtesting procedures (FEDS Staff Working Papers). Retrieved from https:// www.federalreserve.gov/pubs/ feds/2005/200521/200521pap.pdf

7. Chifurira, R., \& Chinhamu, K. (2017). Using the generalized Pareto and Pearson type-iv distributions to measure valueat-risk for the daily South African mining index. Studies in Economics and Econometrics, 41(1), 33-54. https://doi.org/10.10 80/10800379.2017.12097307

8. Chifurira, R., \& Chinhamu, K (2019). Evaluating South Africa's market risk using asymmetric power auto-regressive conditional heteroscedastic model under heavy-tailed distributions. Journal of Economic and Financial Sciences,
12(1), 475. https://doi.org/10.4102/ jef.v12i1.475

9. Coles, S. (2001). An Introduction to Statistical Modelling of Extreme Values. London: SpringerVerlag. Retrieved from https:// link.springer.com/content/pdf /10.1007\%2F978-1-4471-3675-0. pdf

10. Ding, Z., Granger, C. W., \& Engle, R. F. (1993). A long memory property of stock market returns and a new model. Journal of Empirical Finance, 1(1), 83-106. https://doi.org/10.1016/09275398(93)90006-D

11. Dwarika, N., Moores-Pitt, P., \& Chifurira, R. (2021). Volatility dynamics and the risk-return relationship in South Africa: A GARCH Approach. Investment Management and Financial Innovations, 18(2), 106-117. http://dx.doi.org/10.21511/ imfi.18(2).2021.09

12. Embrechts, P., Kluppel, C., \& Mikosh, T. (1997). Modelling Extremal Events: For Insurance and Finance. In: Pricing Insurance Derivatives: The Case of CAT Futures (Chapter 3). Berlin: Springer-Verlag. Retrieved from https://www.springer.com/gp/ book/9783540609315

13. Embrechts, P., Resnick, S., \& Samorodnitsky, G. (1999). Extreme value theory as a risk management tool. North American Actuarial Journal, 3(2), 30-41. https://doi.org/10.1080/10920277. 1999.10595797

14. Escanciano, J., \& Olmo, J., (2010). Backtesing parametric valueat-risk with estimation risk. Journal of Businesse Economic Statistics, 28(1), 36-51. https://doi. org/10.1198/jbes.2009.07063

15. Fama, E. (1965). The behavior of stock market prices. Journal of Business, 38(1), 34-105. Retrieved from http://www.e-m-h.org/ Fama65.pdf

16. Glosten, L., Jagannathan, R., \& Runkle, D. (1993). On the relation between the expected value and the volatility of the nominal excess return on stocks. The Journal of Finance, 48(5), 1779-1801. https:// doi.org/10.1111/j.1540-6261.1993. tb05128.x

17. Ilupeju, Y. E. (2016). Modelling South Africa's market risk using the APARCH model and heavy-tailed distributions (Master's Thesis). University of KwaZulu-Natal. Durban. South Africa. Retrieved from https://researchspace.ukzn. ac.za/handle/10413/15574

18. Jafari, G., Bahraminasab, A., \& Norouzzadeh, P. (2007). Why does the Standard GARCH $(1,1)$ model work well? International Journal of Modern Physics C, 18(7), 1223-1230. https://doi. org/10.1142/S0129183107011261

19. Katsenga, G. (2013). Value at risk (VaR) backtesting' Evidence from a South African market portfolio' (Doctoral Thesis). Retrieved from http://wiredspace.wits.ac.za/ handle/10539/14200

20. Kupiec, P. (1995). Techniques for verifying the accuracy of risk measurement models. The Journal of Derivatives, 3(2), 73-84. https:// doi.org/10.3905/jod.1995.407942

21. Levy, P. (1925). Calcul des Probabilites. Gauthier-Villars et Cie.

22. Mandelbrot, B. B. (1963). The variation of certain speculative prices. Journal of Business, 36(4), 394-419. http://dx.doi. org/10.1086/294632

23. McNeil, A., \& Frey, R. (2000). Estimation of tail-related risk measures for heteroscedastic financial time series: an extreme value approach. Journal of Empirical Finance, 7(3-4), 271-300. https://doi.org/10.1016/S09275398(00)00012-8

24. McNeil, A., Frey, R. \& Embrechts, P. (2015). Quantitative risk management: concepts, techniques and tools-revised edition. Princeton university press. Retrieved from https:// www.researchgate.net/publication/235622467_Quantitative_Risk_Management_Concepts_Techniques_and_Tools 
25. Mzamane, T. P., Achia, T., \& Mwambi, H. (2013). Garch modelling of volatility in the Johannesburg Stock Exchange index (Master's Thesis). University of KwaZulu-Natal. Durban. South Africa. Retrieved from http://hdl. handle.net/10413/10232

26. Naradh, K., Chinhamu, K., Chifurira, R., \& Hammujuddy, M. (2016). Multivariate Elliptically Contoured Stable Distributions with Applications to BRICS Financial Data (Master's Thesis). University of KwaZulu-Natal. Durban. Retrieved from https:// researchspace.ukzn.ac.za/bitstream/handle/10413/15527/ Naradh_Kimera_2016.pdf

27. Nel, C., Chapman, M., \& GarnettBennett, J. (2020). Financial Market Impacts of COVID-19. PwC Inc, South Africa. Retrieved from https://www.pwc.co.za/ en/assets/pdf/financial-marketimpacts-of-covid-19.pdf

28. Nelson, D. B. (1991). Conditional heteroskedasticity in asset returns: A new approach. Econometrica, 59(2), 347-370. Retrieved from http://www.finance.martinsewell. com/stylized-facts/distribution/ Nelson1991.pdf
29. Nguyen, T., \& Sampson, A. (1991). A note on characterizations of multivariate stable distributions. Annals of the Institute of Statistical Mathematics, 43(4), 793-801. Retrieved from https:// www.ism.ac.jp/editsec/aism/ pdf/043_4_0793.pdf

30. Nolan, J. (2001). Maximum likelihood estimation and diagnostics for stable distributions. In Lévy processes (pp. 379-400). Boston, MA: Birkhäuser. Retrieved from https://link.springer.com/chapter/10.1007/978-1-4612-0197-7_17

31. Nolan, J. (2003). Modeling financial data with stable distributions. In Handbook of heavy tailed distributions in finance (pp. 105-130). NorthHolland. https://doi.org/10.1016/ B978-044450896-6.50005-4

32. Nolan, J. (2013). Financial modeling with heavy-tailed stable distributions. WIREs Computational Statistics, 6(1), 45-55. https://doi.org/10.1002/ wics. 1286

33. Nolan, J. (2020). Univariate Stable Distributions: Models for Heavy Tailed Data. Springer Nature. Retrieved from https://www.springer.com/gp/ book/9783030529147

34. Pickands, J. (1975). Statistical inference using extreme order statistics. Annals of Statistics, 3(1), 119-131. http://dx.doi.org/10.1214/ aos/1176343003

35. Ren, F., \& Giles, D. E. (2010). Extreme value analysis of daily Canadian crude oil prices. Applied Financial Economics, 20(12), 941-954. https://doi. org/10.1080/09603101003724323

36. Tian, G. (2016). Parameter Estimation for Stable Distribution: Spacing based and Indirect Inference (Doctoral Thesis). UC Santa Barbara. Retrieved from https://alexandria.ucsb.edu/downloads/bn999696f

37. Tsay, R. S. (2013). Multivariate time series analysis: with $R$ and financial applications. John Wiley \& Sons. Retrieved from https:// www.wiley.com/en-us/Multivariat$\mathrm{e}+$ Time + Series+Analysis\%3A+Wit $\mathrm{h}+\mathrm{R}+$ and + Financial+Applications -p-9781118617908

38. Zakoian, J. (1994). Threshold heteroscedasticity models. Journal of Economic Dynamics, 18(5), 931955. https://doi.org/10.1016/01651889(94)90039-6 